median was 40 . In univariate analyses, associations with $p<0.05$ were observed between pt-perceived coping $(p=0.0008)$, erosive disease $(p=0.03)$ and DAS28 remission $(p=0.05)$ and a high PEPPI-5; associations with $p<0.2$ were observed for older age $(\mathrm{p}=0.07)$ and $\mathrm{HAQ}-\mathrm{DI} \leq 0.5(\mathrm{p}=0.12)$. In multivariate analyses, the only factor associated with high PEPPI-5 was pt-perceived coping (odds ratio $[95 \% \mathrm{Cl}]=0.85[0.76-0.96] ; \mathrm{p}=0.007$ )

Conclusions: Among RA pts whose disease was well controlled, pt-perceived pt-phy interactions were good. Pt-perceived coping was associated with better pt-perceived pt-phy interactions, indicating that perhaps pts who felt in control were more at ease with their phy, or vice-versa. The data did not allow us to attribute causality. These elements are important in the shared decision-making process.

References:

[1] www.sanoia.com

[2] Gossec L. Arthritis Rheum 2016;68:S10.

[3] ten Klooster P. Patient Educ Couns 2012;87(1):125-30.

Acknowledgements: This study was funded by UCB Pharma. We thank the patients and their caregivers in addition to the investigators and their teams who contributed to this study. Editorial services were provided by Costello Medical Consulting.

Disclosure of Interest: L. Gossec Grant/research support from: UCB Pharma, Lilly, Consultant for: AbbVie, BMS, Celgene, Janssen, Novartis, MSD, UCB, C. Desthieux: None declared, A. Cantagrel: None declared, M. Soubrier: None declared, J. M. Berthelot: None declared, J. M. Joubert Employee of: UCB Pharma, B. Combe Grant/research support from: Merck Pfizer Inc, Roche-Chugai, Consultant for: Merck, Pfizer, Roche-Chugai, UCB Pharma, Bristol-Myers Squibb, Celgene, Eli Lilly, Speakers bureau: Merck, Pfizer, Roche-Chugai, UCB Pharma, Bristol-Myers Squibb, Celgene, Eli Lilly, Novartis, W. Czarlewski Employee of: UCB Pharma, D. Wendling: None declared, E. Dernis: None declared, L. Grange: None declared, C. Beauvais Speakers bureau: UCB Pharma, A. Perdriger: None declared, H. Nataf: None declared, M. Dougados Grant/research support from: UCB Pharma, AbbVie, Pfizer, Lilly, Merck, Novartis, H. Servy Shareholder of: Sanoïa platform operating company: e-health services, Employee of: Sanoia DOI: 10.1136/annrheumdis-2017-eular.1973

\section{THU0590 THE USE OF A PORTFOLIO AMONG YOUNG RHEUMATOLOGISTS: RESULTS OF AN EMEUNET SURVEY}

M. Van Onna ${ }^{1}$, F. Sivera ${ }^{2}$, V. Navarro-Compán ${ }^{3}$, E. Nikiphorou ${ }^{4}$, A. Moltó ${ }^{5}$ S. Ramiro ${ }^{6}$ on behalf of the EMEUNET Working Group. ${ }^{1}$ Department of Internal Medicine, division of Rheumatology, Maastricht University Medical Center +, Maastricht, Netherlands; ${ }^{2}$ Rheumatology, Hospital General Universitario de Elda, Alicante; ${ }^{3}$ Rheumatology, la Paz University Hospital, Madrid, Spain;

${ }^{4}$ Rheumatology, Whittington Hospital, London, United Kingdom; ${ }^{5}$ Rheumatology, Cochin Hospital, René Descartes University, Paris, France; ${ }^{6}$ Rheumatology, Leiden University Medical Center, Leiden, Netherlands

Background: Portfolios are increasingly used in medical education. A portfolio may stimulate deep learning, deliver summative assessment and encourage reflection on clinical practice. A portfolio is seen as the key connection between learning at the organizational and the individual level.

Objectives: To (1) explore the perceptions of young rheumatologists about the use of a portfolio and to (2) study the barriers and facilitators when implementing a portfolio at a national and international level.

Methods: A survey was sent by email to all EMEUNET (Emerging EULAR Network) members. EMEUNET is a group of young rheumatologists and researchers within EULAR-member countries. Descriptive statistics were used to analyse initial data collected (Nov-Dec 2016). Weighted averages were calculated (i.e. mean in which each item being averaged is multiplied by a number (weight) based on the item's relative importance).

Results: 132 participants responded $(64 \%$ female; mean age 33.5 years (SD 4.3 years); 34 countries). In total, $56.3 \%$ of participants were working as rheumatologists; $32.8 \%$ were rheumatologists in training. $49.6 \%$ of the participants indicated that a portfolio was already used by rheumatology fellows working at their institution; in $71.9 \%$ of these cases, this portfolio was also used at a national level. $50.4 \%$ of participants did not use a portfolio during their training; of these, $86.7 \%$ (strongly) agreed that a portfolio might be a useful tool.

Several barriers for successful implementation of a portfolio were identified by the participants. The main barrier was that a portfolio was not developed at a national level, and if developed at a national level, there were often no incentives to use it (Table 1). According to participants, the top 3 competencies that should be collected and reflected upon in the portfolio were (weighted average; importance 0 (not important) - 10 (extremely important)): practical skills (e.g. ultrasound) (8.2); correct use of diagnostics and therapeutic armamentarium (7.9); clinical skills (e.g. history taking) (7.8). The skills chosen as the least important to be included in a portfolio were: information on management tasks (6.5); promoting hospital-based care (e.g. writing a protocol) (6.6); theoretical and clinical knowledge (6.7).

Conclusions: A portfolio is generally considered a valuable tool and half of the participants already work with it. However, several barriers may prevent optimal implementation. Developing a core set of rheumatology-oriented competencies and a template for a portfolio to be used across institutions and eventually countries could promote implementation and harmonize training.

Disclosure of Interest: None declared
Table 1. Perceived barriers with regard to the implementation of a portfolio.

\begin{tabular}{|l|l|}
\hline Barrier & $\begin{array}{l}\text { Response* } \\
\text { (n=122) }\end{array}$ \\
\hline Participants who work/ed with a portfolio (n= 58) & $50.0 \%$ \\
\hline No incentives to use it & $46.6 \%$ \\
\hline Limited time & $31.0 \%$ \\
\hline Lack of clarity about how and when to use it & $29.3 \%$ \\
\hline Lack of interest by stake holders & $12.1 \%$ \\
\hline Difficult to access the required forms & \multicolumn{2}{|l}{} \\
\hline Participants who did not work/ed with a portfolio (n=64) & $51.6 \%$ \\
\hline Portfolio not developed on national level & $21.9 \%$ \\
\hline No added value recognized to it & $12.5 \%$ \\
\hline Initiatives, but lack of clarity about how and when to use it & $9.4 \%$ \\
\hline Initiatives, but no incentives to use it & \\
\hline *More than one answer allowed. 10 (7.6\%) participants did not answer the question.
\end{tabular}

DOI: 10.1136/annrheumdis-2017-eular.2280

\section{THU0591 ASSESSING THE READABILITY AND PATIENT COMPREHENSION OF MEDICINE INFORMATION SHEETS PROVIDED TO PATIENTS BY AUSTRALIAN RHEUMATOLOGISTS}

M. Oliffe $^{1}$, J. Johnston ${ }^{2}$, D. Freeman ${ }^{1}$, H. Bagga ${ }^{1}$, P.K. Wong ${ }^{3} .{ }^{1}$ Mid-North Coast Arthritis Clinic, MNCAC; ${ }^{2}$ Faculty of Education, Southern Cross University; ${ }^{3}$ Mid-North Coast Arthritis Clinic, UNSW Rural Clinical School, Coffs Harbour, Australia

Background: Literacy is "the ability to read and use written information and to write appropriately in a range of contexts". ${ }^{1}$ Low literacy is associated with poorer health outcomes, including increased mortality. ${ }^{2}$ Those accessing the healthcare system require adequate literacy to understand written instructions regarding medication, appointments and medication doses. We have previously shown in $>200$ rural and urban Rheumatology patients that $<15 \%$ of patients had low health literacy and $<1 / 3$ of patients incorrectly followed dosing instructions for common Rheumatology drugs. ${ }^{3}$ Up to $24 \%$ of US Rheumatology patients had a reading level of $\leq 8$ th grade. ${ }^{4}$ These findings are concerning, as Rheumatologists often use medications such as MTX or bDMARDS with severe side effects. Rheumatologists often provide written information regarding these medications to patients.

Objectives: To assess i) the readability of Patient Medicine Information Sheets (PMIS) regarding medications provided to patients by Australian Rheumatologists, and ii) patient comprehension of these documents.

Methods: Thirty-one English-language PMIS from the Australian Rheumatology Association (ARA) website were assessed for readability using Readability Studio ${ }^{T M}$ (Oleander Software). This software uses the number of sentences, words, syllables and characters in a sample of writing to estimate the required grade level and reading age of the target population using several readability scales (eg Flesch scale, Gunning Fog and Simple Measure of Gobbledygook, or SMOG).

To assess comprehension, a random sample of 100 patients from MNCAC was asked to read an ARA PMIS about one of the following medications: MTX, NSAIDS, Adalimumab, Abatacept or prednisone. He/she then answered five multiple choice questions about the content. A time limit of 15 minutes for reading the PMIS and answering the questions was allowed.Approval was obtained from the local HREC as a low/negligible risk project. Results are expressed as mean \pm sem.

Results: The mean Flesch scale value (range $0-100,0=$ very confusing; $100=$ very easy) of the 31 PMIS assessed was $51.1 \pm 0.6$ (fairly difficult). The mean FORCAST grade level and reader age was $11 \pm 0$ and $16-17$ years, respectively. The mean Gunning Fog grade level was $11.4 \pm 0.1$ with a reader age of $16-17$ years. The mean SMOG grade level was $11.8 \pm 0.1$ with a mean reader age of $16-17$ years. At time of writing, comprehension was assessed in 7 of the planned 100 patients. So far, the mean number of correct answers was $3.2 \pm 0.5$ (max. score of 5).

Conclusions: The ARA PMIS are suitable for readers who have completed a grade level $\geq 11$ with a reading age $\geq 16$ years. A low literacy population $(<$ grade 8) will probably struggle to understand the content. These findings need to be extended to the PMIS used in other countries and has implications for the design of better patient information material.

References:

[1] Australian Government, Department of Education Employment and Training. The Australian Language and Literacy Policy. Canberra 1991.

[2] Baker DW et al. Arch Intern Med 2007:167:1503-1509.

[3] Wong PK et al. Medicine (Baltimore) 2014 Nov;93(25):e129.

[4] Swearingen CJ et al. J Clin Rheumatol 2010;16:359-364.

Disclosure of Interest: None declared

DOI: 10.1136/annrheumdis-2017-eular.4811 